\title{
Problems of Professional Musical Education Development in the Global Informatization Process
}

\author{
Olga Sizova \\ Department of Production and Music Education \\ Minin Nizhny Novgorod State Pedagogical University \\ Nizhny Novgorod, Russia \\ E-mail: olgasizova88@yandex.ru
}

\begin{abstract}
The article deals with the problems of professional music education development in the context of the global informatization process. The study outlines ways of solving the problems by means of information systems in the sphere of "Music education and art" in professional training of teachers-musicians. Theoretical researches were carried out and these problems were analyzed. Traditional methods of obtaining information at the present stage of society development are not always able to meet the requirements of a modern specialist. The problem of their usage is put forward. The opinions of the leading Russian musicologists about the use of information systems in the selection of musical material are given. The conclusion formulates the necessity of information technologies not only in the search and collection of musical material but in listening as well.
\end{abstract}

Keywords-global informatization; professional music education; information systems; teacher-musician

\section{INTRODUCTION}

Intensive transformation of socio-economic and sociocultural spheres of society predetermined the emergence of a number of prerequisites for a significant change in the technology of professional music education. Informatization is one of the fundamental tendencies of pedagogical education at the present stage of society development [1]. Qualitatively different principles of the organization of all spheres of life in the society aimed at solution of the tasks connected with social activity, ability to adapt and successfully coordinate professional activity are formed. "Informatization is characterized as a process aimed at the creation, development and dissemination of information and communication technologies, which is one of the fundamental factors in the process of socio-economic transformation, crisis management and stabilization of the state economy and the development of the education system" [2].

Music education is a rather complex system, which reflects personal, cultural and aesthetic components.

The modern stage of professional music education development in the framework of global informatization dictates the professional pedagogical community other approaches to training professionals capable of both creative activities and those which are regulated and determined by relevant regulatory and legal documentation, which requirements include the need to develop competence in the field of information technology. In this regard, the need for new methodological approaches and principles focused on the use of creative trends and specialties in educational programs, means and possibilities of information technologies is revealed.

In today's socio-cultural society professionals in the field of culture and art, ready to freely apply in practice the competence demanded in the information space are required. There is a need in teachers-musicians of a new quality able to response rapidly to the changes occurring in science, technology, to solve effectively the problem by means of activation the competences formed in during professional music education.

In the context of constant updating and improvement of technologies, global informatization, modernization of education, the requirements of employers to the level of information competencies formation of future teachers and musicians are changing. In this regard, it is necessary to have already formed creative competencies in the field of musical art and to activate the information component in the process of competencies formation. Students enrolled in programs of musical education studying information systems in the sphere of "Music education and art" are able to solve these problems. Currently, there is no universally recognized formal definition of the concept of the subject area. Unfortunately, there is no meaningful definition of it [3].

It is supposed that the concept of the subject area can not be formalized as a primary concept [4]. Information systems of the subject area "Music education and art", among other things, contain full information about the creative work of a certain composer, necessary during perfection performing, musicological, lecturing, cultural and educational activities.Besides, work with information systems forms certain skills aimed at obtaining information competence.

\section{INFORMATIZATION OF SOCIETY AND EDUCATION}

It is known that informatization of society naturally causes informatization in education and active mastering the information technologies. Working with students, practical 
application of information and communication technologies by a teacher-musician is necessary.

The process of implementation, and then the use of computer technology in education, may be divided into the following key stages:

- electronization;

- computerization;

- informatization.

Let's study the stages. Electronization of the educational process is characterized by the large-scale inclusion of electronic means in training students of technical and later humanitarian specialties. Chronologically, this process can be attributed to the middle of the last century, when scientific and technological progress had an impact on virtually all spheres of society.

Computerization of education occurred in the 70s-90s of the last century and is associated with the emergence of more powerful computers, more advanced software. Computer technology allowed to explore various processes and phenomena in the field of natural, mathematical, humanitarian, pedagogical sciences. Computerization played its role in expanding the profiles and specializations of educational programs.

The stage of informatization of education is characterized by a wide use of information and multimedia technologies, powerful personal computers, etc.

If at the stage of electronization of education students of humanitarian and creative specializations experienced severe difficulties in working with the software, then at the modern stage of informatization of education we can state successful introduction of information technologies in educational process.

With the improvement of computer technologies and universal accessibility their inclusion in the process of professional training of creative specialties students can become a natural phenomenon.

With the help of network means of information technologies there is a possibility of wide access to scientific information, as well as to educational and methodical documentation in various subjects. Besides, these means coordinate organization of the following activities: research, creative, cultural, educational, consulting.

The indicated stages of changes in education directly depend on the processes taking place in the society. Education in a wide aspect, including its branch of professional music education quickly react to the above mentioned changes. In this regard, traditional approaches to the organization of the educational process are also undergoing significant changes.

The accumulated theoretical and practical results show that the global informatization of the educational process in itself creates the necessary conditions for the education of future specialists.

\section{SPECIFIC APPLICATION OF INFORMATION SYSTEMS IN PROFESSIONAL MUSIC EDUCATION}

The problem of information support of musicians' activity was considered in the works of researchers of the mid-twentieth century. The specificity of the formation of the library fund with rich musical resources was described in the thesis of N. In. Gradoboeva [5] A. Z. Erkovetskoe [6]. In these works, the specificity of the traditional model of data collection was deeply investigated. It is known that not always a specialist has enough time to work with the reference material of the archive or library, in this regard, it seems relevant to select the most optimal and acceptable information system, the subject area of which will be focused around the problems of the sphere of musical art and education.

In fact, the user of the information system operates through an electronic device that has outputs through the interface to a huge number of databases. A musician using third-party databases on the Internet must have certain knowledge, abilities and skills. One of the main rules which one must strictly observe is the use of legitimate databases. For example, when creating your own website, as well as any other individual product, it is necessary to respect, first of all, the exclusive copyright and other intellectual rights of other users of the global network, which consists of a set of information systems, networks and is in the broad sense of the word information technology.

There are numerous classifications of information systems. On the functional basis they distinguish juridical, bibliographic, medical, statistical, etc.

According to the degree of automation, there are manual (library catalog), automated (using activities of the subject), automatic information systems (completely excluding human participation).

Information systems the purpose of which is to provide juridical, economic, sociological, medical, bibliographic activities are widely used. The leading role among such systems is played by juridical information retrieval systems, statistical data analysis systems for optimization and solution of problems related to order processing, production planning, calculation of taxes and wages, personnel accounting.

In order to realize effectively professional activity it is important for a teacher-musician to possess a vast amount of information in the subject "Music education and art".

Many musicologists, including E. V. Nazaikinsky [7], V. Medushevsky [8], wrote that information technologies can be used to study the means of musical expressiveness. In this regard, it becomes obvious that there is a need to introduce electronic resources into educational process of musicalhistorical, cultural training of a teacher-musician, the use of which can become one of the effective methods of their professional competence formation. The information on an electronic resource can supplement or extend traditional approaches, reflecting the rich experience gained in the development of music education and art. 
A modern teacher-musician is not only a specialist, skillfully interpreting musical works of different epochs, genres, styles, but also a specialist, whose duties include the ability to plan the educational process, the individual educational trajectory of a student. This is a person able to manage educational systems and programs. The above activities make it possible to use time and effort economically and rationally. Music pedagogy, which is a branch of pedagogical science, aims to solve the problem of studying, developing, designing effective ways of organizing professional music education. This suggests that a modern teacher-musician is capable of rapid processing, critical evaluation, analysis of the information and is already on the basis of the all above mentioned to create and implement successfully the work program of the discipline. The use of information systems can be effective in management and organization of the future professional activity.

The use of modern sources of obtaining the necessary data can quickly provide the necessary information in any place and time. The specificity of the obtaining information can be quite different: from the basics of musical-theoretical, musical-historical training to audio recordings of musical works in different treatments and interpretations. Thus, for teachers-musicians, the most important thing in the implementation of performing training is the availability of not only musical material, but also different versions of interpretations of musical works, as well as their analysis and characteristics.

Working process of on a piece of music consists of wellknown stages, which include a large amount of information [9]. Choosing a work for its mastering and later performance, a student faces a lot of difficulties relating to the process of studying the musical text. Work on musical material, includes work on the content and stylistic sides of the musical work, as well as an adequate choice of tempo, fingering, sound production, The students have a task not only to find musical material, but also works that analyze the creative activity of a particular author belonging to a certain trend; sources that give a complete picture of the aesthetics of the period of the work creation.

Besides, for a stylistically competent performance, in the process of work at the composition a comparative analysis of different editions and interpretations is necessary. It is obvious that a student has to spend a lot of time to carry out all these types of work. It may be assumed that the solution to this problem may be the use of the most optimal information system based on the database technology, in which all information will be structured according to the key concepts most often used by professionals in this field. In this regard, the use of the most effective information system in music education will help students to specify activities in the field of audio material, as well as to optimize the time spent on searching for information, especially in modern education when every student has the access to databases and information systems.

\section{CONCLUSION}

To increase the level of efficiency of a specialist in any field of professional activity, it is necessary to improve constantly the skills, mastering an increasing amount of the necessary information in the subject area in which helshe realizes him herself. In this regard, the ability to use information systems freely can be not only a means of achieving a positive result, but also a necessary condition for improving professional skills.

The problems of teachers-musicians professional training in modern dynamical social transformations and rapid development of technologies are currently not fully investigated. Modern approaches to the organization of training process aimed at the education of a creative personality of a graduate, capable of freely solving any professional problems. Qualification of a teacher-musician is determined by his her ability to develop and implement programs, to implement presentation activities in the field of culture and education, the ability to think creatively, to take the initiative in the modern information society, saturated with innovative technologies.

The tendency to fusion and interaction of traditional ways of teaching and modern information computer technologies with innovative methods of pedagogy to increase the efficiency and quality of educational programs, is one of the most important tasks of modern professional music education and pedagogy. The relevance of information technology usage is due to the public demand to improve the quality of the educational process including professional music education.

The use of information technologies in the educational process of institutions implementing creatively orientated educational programs is extremely important at the present stage of social development, in the situation when the youth, which is the reflection of their time, actively uses the full range of modern information technologies in everyday life.

\section{REFERENCES}

[1] Slastenin V. A. et al. Pedagogy Textbook for students of higher pedagogical institutions / V. A. Slastenin, I. F. Isaev, E. N. Shiyanov; ed. by V. A. Slastenin. M.: publishing center "Academy", 2002. 576 p.

[2] M. L. Gruzdeva, M.Yu. Svinukhova. The use of information technologies for the formation of professional mobility of graduates of universities /Bulletin of the North Caucasus humanitarian Institute. 2013. No. 1 (5). P. 219-223.

[3] G. Vostrov, E. Malakhov, K. Kornilova3roblems of modeling of subject areas in information systems URL http://www.codenet.ru/progr/other/modeling-problems/ (accessed: 18.09.2018).

[4] M. S. Tsalenko. Modeling semantics in databases. - M.:Science. $1989-287 \mathrm{p}$.

[5] N. V. Grabodoyeva. Information needs of specialists in the field of musical art :Prob. and methods of study. Scientific library of dissertations and author's abstracts of $\mathrm{PhD}$ thesis: 05.25.03 / Grabodoyeva N. V. St. Petersburg, 1996. 277 p.

[6] A. Z. Yurkovetskaya. Improvement of library-bibliographic service of amateur musical ensembles through the study of the specificity of 
their information needs: $\mathrm{PhD}$ dissertation: 05.25.03. Moscow, 1981. $230 \mathrm{p}$.

[7] E. V. Nazaykinsky. Musical perception as a problem of musicology / E. V. Nazaikinsky / / Perception of music: collection of articles. Moscow: Music, 1980. - P. 91-110.

[8] V. MedushevskyIntonational form of music. M.: Composer, 1993. $268 \mathrm{p}$.

[9] E. J. Lieberman. Creative work of a pianist at the author's text. Moscow: Music, 1988. 234 p.

[10] N. S. Alexandrova. Education in modern conditions of informatization / N. S. Alexandrova, V. N. Onoshko / / Pedagogy. Society. Law. 2015.- No.1. P. 4-19.

[11] T. D. Akhmedzhanova. Formation of informational culture of students through problematization of the educational situation: $\mathrm{PhD}$ dissertation ...: 13.00.01 / T. D. Akhmedzhanova. Chita, 2009. 215 p.

[12] F. S. Voroysky. Informatics: encyclopedia. systemat. words.-utr.:intr. to modern inform. and telecommunication technology in terms and facts. M.: Fizmatlit, 2006. 945 p. URL: http://old.nsuem.ru/edu/library/Electronic_library/Internetresursy/Slovari/Vorojskij_Informatika.pdf(accessed: 17.04.2015).

[13] R. A. Ulyanova. To the 60 -anniversary of the founding of the allRussian creative Association of musicians-teachers at the Central House of art workers (some aspects of traditions and innovation) / R. A. Ulyanova // Modern musical pedagogy: a dialogue of traditions and schools / nngc named after. M. I. Glinka. Nizhny Novgorod: Nizhny Novgorod Conservatory publ., 2015. P. $164-171$.

[14] A. R. Ganeyeva. Information technologies in pedagogical high school: organization of independent work of students in geometry: $\mathrm{PhD}$ dissertation: 13.00.08, 13.00.02 / R. Taneyeva. Elabuga, 2005. 249 p.

[15] D. N. Gribkov. Electronic information resources of libraries: on the problem of integration/ / Library science. 2008. No. 4. P. 48-51.

[16] L. H. Zainutdinova. Diagnosis of restrictions on the development of students ' thinking in the development of modern information systems on the example of classification problem // A. I. Fedoseyev // Journal "Science and education" No.3 2013 p. 22-33.

[17] G.A. Kruchinin. Readiness of a future teacher to use new information and communication technologies / G.A. Kruchinin. Monograph. M.: Moscow state pedagogical University. Publishing house of Moscow state pedagogical University named after V. I. Lenin. 1996. 176 p.

[18] I. V. Zabolotskaya. Abstract of the thesis for $\mathrm{PhD}$ "New informational technologies in music education", St. Petersburg-2000.

[19] O. A. Kozlov. Prospects for the development of education in the informational society / O. A. Kozlov // Informational technologies in designing and manufacturing, 2001, No. 1. P. 45-52.

[20] Information resources.

[21] Bekenova D.U., MukhatayevaZh. A. Informational technology in music education [Text] // Actual problems of pedagogy: materials of the III international scientific. conf. (Chita, February 2013). - Chita: Publishing house Young scientist, 2013. URL https://moluch.ru/conf/ped/archive/67/3328/ (accessed: 20.09.2018).

[22] Zvereva Y. S. Informatization of education // Young scientist. - 2016. No.6.3. P. 23-26. URL https://moluch.ru/archive/110/27234/ (accessed: 20.09.2018). 